\title{
Are G3 ENETS neuroendocrine neoplasms heterogeneous?
}

\section{Fritz-Line Vélayoudom-Céphise', Pierre Duvillard ${ }^{2}$, Lydia Foucan ${ }^{3}$, Julien Hadoux', Cecile N Chougnet ${ }^{1}$, Sophie Leboulleux', David Malka ${ }^{4}$, Joël Guigay ${ }^{5,8}$, Diane Goere ${ }^{6}$, Thierry Debaere ${ }^{7}$, Caroline Caramella ${ }^{7}$, Martin Schlumberger', David Planchard ${ }^{5,8}$, Dominique Elias $^{6}$, Michel Ducreux ${ }^{4,8}$, Jean-Yves Scoazec ${ }^{2}$ and Eric Baudin'}

Departments of ${ }^{1}$ Nuclear Medicine and Endocrine Oncology ${ }^{2}$ Pathology, Institut Gustave Roussy, 39 rue Camille Desmoulins, 94805 Villejuif Cedex, France

${ }^{3}$ Department of Biostatistics and Epidemiology, Research Group ECM, University Hospital of Pointe-à-Pitre, Guadeloupe, France

Departments of ${ }^{4}$ Gastroenterology ${ }^{5}$ Thoracic Oncology ${ }^{6}$ Digestive Surgery ${ }^{7}$ Medical Imaging,

Institut Gustave Roussy, Villejuif, France

${ }^{8}$ Faculté de Médecine Paris Sud, Université Paris 11, Le Kremlin-Bicêtre, France
Correspondence should be addressed to E Baudin Email

Eric.BAUDIN@

gustaveroussy.fr

\begin{abstract}
The new WHO classification of gastroenteropancreatic (GEP) neuroendocrine tumors (NET) implies that G3 neoplasms with mitotic index $>20$ and/or Ki67 index $>20 \%$ are neuroendocrine carcinomas (NEC), described as poorly differentiated, small or large cell types, by analogy with lung NEC. To characterize the subgroup of non-small-cell-type GEP and thoracic NET with mitotic index $>20$ and/or Ki67 $>20 \%$ according to their pathological features, response to cisplatin and overall survival (OS). We reviewed pathological and clinical presentation of G3 non-small-cell-type NET referred to our institution for 5 years. Data from 166 patients with metastatic thoracic and GEP-NET were collected. Twenty-eight patients $(17 \%)$ fulfill the inclusion criteria. Tumors were classified as well-differentiated NET (G3-WDNET) in $42.8 \%$ of cases and poorly differentiated, large-cell NEC (G3-LCNEC) in 57.2\% of cases. Plasma chromogranin A or neuron-specific enolase were elevated in 42 and $25 \%$ respectively of G3-WDNET and 31 and $50 \%$ of G3-LCNEC. Somatostatin receptor scintigraphy was positive in 88 and $50 \%$ of G3-WDNET or G3-LCNEC respectively. Complete or partial response to cisplatin was observed in $31 \%$ of cases, all classified as G3-LCNEC. The median OS was 41 months for G3-WDNET but 17 months for G3-LCNEC $(P=0.34)$. Short survival was observed in $25 \%$ of G3-WDNET but $62.5 \%$ of G3-LCNEC patients ( $P=0.049$ ). G3 ENETS GEP and thoracic neuroendocrine neoplasms (NEN) could constitute a heterogeneous subgroup of NEN as regards diagnosis, prognosis, and treatment. If confirmed, future classifications may consider splitting them into two groups according to their morphological differentiation.
\end{abstract}

\section{Key Words}

- grade 3 neuroendocrine carcinoma

- mitotic count

- Ki67 index

- WHO classification

\section{Introduction}

Gastroenteropancreatic neuroendocrine neoplasms (GEP-NEN) are rare tumors defined by the expression of specific diagnostic biomarkers (Baudin 2007, Modlin et al.
2008, Yao et al. 2008). Their prognosis is best characterized by their heterogeneity. As demonstrated in several studies, the prognostic outcome is first driven by the 
morphological differentiation with two tumor subsets, the poorly and the well-differentiated ones (Madeira et al. 1998, Travis et al. 1998, Rindi et al. 1999, Lepage et al. 2004, Lim et al. 2005, Faggiano et al. 2007). Indeed, whatever the stage and primary location be, poorly differentiated GEP-NEN have a poorer outcome than well-differentiated ones (Madeira et al. 1998, Mitry et al. 1999, Rindi et al. 1999, Lepage et al. 2004, Faggiano et al. 2007, Yao et al. 2008). In addition, the differentiation status constitutes a predictive factor of response to cisplatin-based chemotherapy (Mitry et al. 1999, Pavel et al. 2012). Several studies demonstrated that poorly differentiated NEN respond to cisplatin in more than $50 \%$ of cases against $<15 \%$ for well-differentiated ones (Moertel et al. 1991, Mitry et al. 1999, Yamazaki et al. 2005, Hainsworth et al. 2006, Hentic et al. 2011).

Recently, in well-differentiated NEN, the prognostic relevance of the proliferation indexes, including the mitotic index and the Ki67 index, has been highlighted, especially in tumors of lung or pancreatic origin (Travis et al. 1998, Ekeblad et al. 2008, Strosberg et al. 2009, Panzuto et al. 2011). The importance of proliferation indexes has been formalized and standardized by the European Neuroendocrine Tumor Society (ENETS), with the proposal of an ENETS histological grade for GEP-NEN (Rindi et al. 2006, 2007). In 2010, the revised WHO classification establishes the role of proliferative indexes even more pivotal. Indeed, this new classification defines three groups of tumors based on the combination of morphological features and of mitotic count and/or Ki67 index (Rindi et al. 2010): neuroendocrine tumor (NET)/neoplasm G1, NET/neoplasm G2, and neuroendocrine carcinomas (NEC). In this new classification, the grading refers not only to the proliferative index but also to morphological features. Sensu stricto, NEC is defined by a poorly differentiated morphology of either large or small cell type; for this subset, the proliferative indexes are not explicit diagnostic criteria, unlike the other two categories. However, as it does not belong to the WHO G1 and G2 subgroups, it is assumed that in NEC G3 neoplasms, mitotic index and/or Ki67 index are above 20 or $>20 \%$ respectively. So far, no definitive evidence suggests that, despite their prognostic relevance, proliferative indexes alone are predictive factors of response to chemotherapy, in contrast to the differentiation status.

The revised WHO classification of GEP-NET is much similar to that of lung and other thoracic NET but differs on some points. The most important differences are as follows: i) the use of only mitotic index and not Ki67 index for lung tumor grading and ii) a lower cutoff between low-grade and high-grade lung tumors, established at ten mitoses per 10 high-power fields (HPF). While the WHO classification of GEP-NET uses the terminology similar to that of the WHO classification of lung tumors for the distinction of high-grade tumors into two types, small cell and large cell, no diagnostic criteria have been provided for the reliable identification of GEP large-cell NEC (Rindi et al. 2010).

The WHO 2010 scheme makes it possible to classify most cases of GEP-NEN. However, in our local experience, some cases do not fit within the current classification: whereas they are grade 3 , they do not present a poorly differentiated morphology and therefore cannot be comfortably classified neither as NEC nor as NET/NEN. As this conveys major consequences regarding the therapeutic management, especially as regards the decision of cisplatin-based chemotherapy, we decided to review our experience with this group of patients. We therefore performed a single-center retrospective study, which examined the pathological, diagnostic, and prognostic criteria of patients with tumors characterized by high-proliferative indexes, corresponding to the ENETS histological grade G3, as defined for GEP-NET, whatever the primary location. Small-cell-type NEC were excluded from the study, as they represent a well-defined and usually easily recognizable entity.

\section{Subjects and methods}

\section{Population}

GEP and thoracic NEN patients with metastatic disease, without prior systemic therapy and referred to Gustave Roussy Institute between 2000 and 2005 for therapeutic management, were reviewed. Inclusion criteria were as follows: i) neuroendocrine nature of the tumor confirmed by the immunohistochemical detection of at least two neuroendocrine markers including chromogranin A, synaptophysin, and/or N-CAM (Baudin et al. 1998); ii) confirmed mitotic index and/or Ki67 index respectively higher than 20 mitotic counts per $10 \mathrm{HPF}\left(2 \mathrm{~mm}^{2}\right)$ and/or $>20 \%$ positive cells in at least 2000 tumor cells (whatever the primary location); iii) stage III or stage IV ENETS metastatic neoplasms; iv) entire follow-up in our institution until death; and v) tissue material available for histological review and additional immunohistochemical studies, if necessary. Exclusion criteria were as follows: i) confirmed diagnosis of small-cell NEC or Merkel cell carcinoma; ii) mixed tumors; iii) patients referred after first-line treatment, and iv) absent or insufficient specimen for pathological review. All patients signed an informed consent.

Published by Bioscientifica Ltd 


\section{Pathological criteria}

Well and poorly differentiated NEN were distinguished on the basis of morphological criteria, in keeping with, or adapted from, current classifications (Travis et al. 1999, Solcia et al. 2000). Slides were independently reviewed by two pathologists, with expertise in the field (P D and $\mathrm{J}-\mathrm{Y} \mathrm{S}$ ); in case of discrepancy, a consensus was reached through the simultaneous examination of the case by both pathologists.

Well-differentiated NEN were identified by the combination of the following features (Fig. 1): i) presence of a typical neuroendocrine architectural pattern with organoid features (usually insular, trabecular or glandular, sometimes solid), ii) tumor cells with low nucleocytoplasmic ratio, abundant eosinophilic or amphophilic cytoplasm, and ovoid nuclei with salt and pepper chromatin containing well-defined nucleoli. Nuclear atypia and cell pleomorphism could be present. Tumor necrosis, if present, was only focal. This tumor subset will thereafter be referred to as 'well-differentiated neuroendocrine tumors (WDNET) with high proliferative rate' or 'G3-WDNET'.

Features used for the diagnosis of poorly differentiated NET, large cell type, were essentially as those proposed for lung tumors (Fig. 1): i) nodular or solid architecture, usually devoid of organoid features, with rosette formation or palisading; ii) large-sized tumor cells (by convention, larger than three lymphocytes), with usually high nucleocytoplasm ratio, distinctive nuclear features (including the presence of well-visible nucleoli and frequent atypia), and variable amounts of cytoplasm, often basophilic; and iii) multifocal or extensive tumor necrosis. This tumor subset will thereafter be referred to as 'G3 large-cell NEC (G3-LCNEC)'.

As proposed for GEP tumors, mitotic counts were performed in $50 \mathrm{HPF}$ and reported as the sum of the ten highest counts, in a total surface corresponding to $2 \mathrm{~mm}^{2}$ (1 $\mathrm{HPF}=0.2 \mathrm{~mm}^{2}$ ). For $\mathrm{Ki} 67$ index evaluation, the mouse MAB MIB-1 was applied to formalin-fixed, paraffin-embedded tissue sections (clone MIB-1, Dako, Glostrup, Denmark). Evaluation of Ki67 expression was performed in at least 2000 tumor cells, according to the current recommendations for GEP tumors (Rindi et al. 2006, 2010).

\section{Diagnostic and prognostic characterization}

The following features were recorded in all patients: age, gender, presence of functioning syndromes and inherited genetic syndromes, primary and metastatic locations, ENETS TNM stage, plasma levels of CGA (CGA-RIACT, CIS Bio International, Gif-sur-Yvette, France, normal $<100 \mu \mathrm{g} / 1$ ), neuron-specific enolase (NSE; Cispack NSE, Cis Bio International; normal $<12.5 \mu \mathrm{g} / \mathrm{l})$, urine levels of 5-hydroxyindoleacetic acid (5HIAA; reagent kit, BioRad; normal $<42 \mu \mathrm{mol} / 24 \mathrm{~h}$ ), and status of uptake at somatostatin receptor scintigraphy (SRS) with indium111-pentetreotide and/or fluorodeoxyglucose positron emission tomography (FDG-PET) as previously defined (Baudin et al. 1998, Dromain et al. 2005, Leboulleux et al. 2008, Abgral et al. 2011).
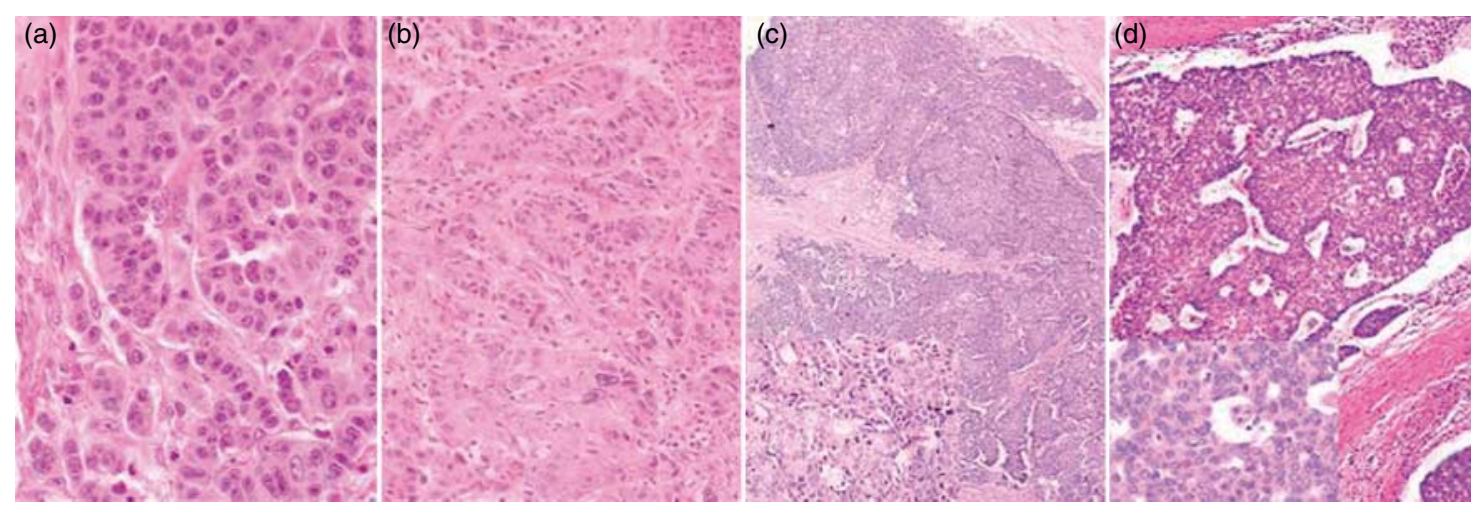

\section{Figure 1}

Morphological presentation of G3 GEP-NEN. All the tumors illustrated here are of histological grade 3 . In a and $b$, neoplasms are morphologically well differentiated (G3-WDNET). The architecture is trabecular in $a$; in $b$, tumor cells form small nests; they are large, eosinophilic, with nucleolated nuclei; there is marked nuclear pleomorphism; numerous mitoses and apoptotic figures are visible. In c and d, neoplasms are classified as poorly differentiated, large cell type (G3-LCNEC); tumor cells form masses of large cells, with high nucleocytoplasmic ratio (insets); palisading or rosette formation are visible. Hematoxylin-eosin-saffron, original magnifications: a, $\times 320 ; b, \times 300 ; c, \times 100 ; d, \times 140$ (inset, $\times 280$ ). 
All therapeutic sequences were recorded and a special focus was made on cisplatin-based chemotherapy, prescribed as described previously (Mitry et al. 1999). Imaging follow-up was performed every 2-3 months with thoracic and abdomen CT or abdomen MRI. Type and results of conventional imaging were reviewed and classified according to the RECIST 1.0 classification. According to RECIST, results were classified as partial response (PR) if the sum of the target lesions decreased more than 30\%; complete response (CR) if all target lesions disappeared; progressive disease if progression exceeded 20\%; stabilization (S) in between (Therasse et al. 2000). Progression-free survival was defined as the time between chemotherapy initiation and the first subsequent event: progression or death from any cause. Vital status on December 31, 2010 and 2-year survival were recorded.

\section{Statistical analysis}

Patients were characterized in terms of pathological, clinical, biological, and imaging features. As both pathological features of well-differentiated (WD) or poorly differentiated (PD) tumors were found compatible with G3 thoracic and GEP-NEN, we further analyzed the impact of the differentiation status on the above-mentioned characteristics as well as on the response to cisplatinbased chemotherapy whatever the primary location. Categorical variables were reported as numbers (percentage) and quantitative variables as median value (mean, range) because of a non-normally distributed data. Comparisons between groups were performed respectively by Fisher exact test and Mann-Whitney $U$ test. In addition, the influence of the tumor differentiation status

Table 1 Characteristic of the study population according to the tumor differentiation status.

\begin{tabular}{|c|c|c|c|c|}
\hline Characteristics & $\begin{array}{l}\text { Total } \\
n(\%)\end{array}$ & $\begin{array}{l}\text { Well differentiated } \\
\qquad n(\%)\end{array}$ & $\begin{array}{l}\text { Poorly differentiated } \\
\qquad n(\%)\end{array}$ & $\boldsymbol{P}$ \\
\hline Number (evaluable) & 28 & 12 & 16 & \\
\hline Age: median (28) & 55 years (29-79 years) & 56 years & 55 years & 0.99 \\
\hline Male (28) & $22(78.5 \%)$ & $10(83 \%)$ & $12(75 \%)$ & 0.67 \\
\hline Functioning tumors (28) & $4(14 \%)$ & $3(25 \%)$ & $1(6 \%)$ & 0.28 \\
\hline \multicolumn{5}{|l|}{ Primary (28) } \\
\hline Pancreas & $9(32 \%)$ & $7(59 \%)$ & $2(13)$ & - \\
\hline Lung & $2(7 \%)$ & $1(8 \%)$ & $1(6)$ & - \\
\hline Thymus & $2(7 \%)$ & $2(17 \%)$ & 0 & - \\
\hline Larynx & $3(11 \%)$ & $1(8 \%)$ & $2(13)$ & - \\
\hline Rectum & $1(4 \%)$ & 0 & $1(6)$ & - \\
\hline Others & $4(14 \%)$ & 0 & $4(25)$ & - \\
\hline Unknown & $7(25 \%)$ & $1(8 \%)$ & $6(37)$ & - \\
\hline ENETS stages & & & & - \\
\hline III & $4(14 \%)$ & 0 & $4(25 \%)$ & - \\
\hline IV & $24(86 \%)$ & $12(100 \%)$ & $12(75 \%)$ & - \\
\hline \multicolumn{5}{|l|}{ Metastatic sites (28) } \\
\hline Liver & $18(64 \%)$ & $7(58 \%)$ & $11(69 \%)$ & 0.48 \\
\hline Lung & $5(18 \%)$ & $1(8 \%)$ & $4(25 \%)$ & 0.46 \\
\hline Lymph nodes & $22(79 \%)$ & $9(75 \%)$ & $13(81 \%)$ & 0.5 \\
\hline Bone & $9(32 \%)$ & $3(25 \%)$ & $6(38 \%)$ & 0.99 \\
\hline \multicolumn{5}{|l|}{ Biomarkers (28) } \\
\hline Plasmatic CGA > $100 \mu \mathrm{g} / \mathrm{l}$ & $10(36 \%)$ & $5(42 \%)$ & $5(31 \%)$ & 0.67 \\
\hline Plasmatic NSE $>12.5 \mu \mathrm{g} / \mathrm{l}$ & $11(39 \%)$ & $3(25 \%)$ & $8(50 \%)$ & 0.36 \\
\hline Urinary $5 \mathrm{HIAA}>42 \mu \mathrm{mol} / 24 \mathrm{~h}$ & $4(14 \%)$ & $3(25 \%)$ & $1(6 \%)$ & 0.28 \\
\hline \multicolumn{5}{|l|}{ Functional imaging } \\
\hline SRS uptake $(n=14)$ & $10(71 \%)$ & $7 / 8(88 \%)$ & $3 / 6(50 \%)$ & 0.03 \\
\hline PET-FDG uptake $(n=6)$ & $6(21 \%)$ & $3 / 12(25 \%)$ & $3 / 16(19 \%)$ & 0.66 \\
\hline \multicolumn{5}{|l|}{ Previous treatments (28) } \\
\hline Somatostatin analog & $4(14 \%)$ & $4(14 \%)$ & 0 & 0.12 \\
\hline External radiotherapy & $15(54 \%)$ & $5(54 \%)$ & $10(62 \%)$ & 0.34 \\
\hline Liver chemoembolization & $6(21 \%)$ & $3(21 \%)$ & $3(19 \%)$ & 0.43 \\
\hline $\begin{array}{l}\text { Follow-up months: median } \\
\text { (range) }\end{array}$ & $23(4-86)$ & $37(9-72)$ & $21(4-86)$ & 0.25 \\
\hline OS months: median (range) & $29(1-143)$ & $41(7-143)$ & $17(1-113)$ & 0.34 \\
\hline
\end{tabular}

CGA, chromogranin A; NSE, neuron-specific enolase; SRS, somatostatin receptor scintigraphy; In-111, indium 111.

http://erc.endocrinology-journals.org DOI: 10.1530/ERC-13-0027
(C) 2013 Society for Endocrinology Printed in Great Britain
Published by Bioscientifica Ltd. 
defined as WD or PD on thoracic and GEP-NEN prognosis was analyzed. The Kaplan-Meier method was used to estimate the survival. Median overall survival (OS) was analyzed as defined by time between the date of metastases until the date of death or end of the study. In addition, the percentage of patients alive after 2 years was determined. The SPSS, version 18.0, statistical software package (SPSS, Inc.) was used for the data analyses. Statistical significance was set at $P \leq 0.1$.

\section{Results}

\section{Study population}

The files of 166 successive patients referred to the Gustave Roussy Institute between 2000 and 2005 for a metastatic, therapy-naive, thoracic, or GEP-NEN were checked. Twenty-eight patients fulfilled the inclusion criteria and were included in the study. Their characteristics are reported in Table 1 . Their median age at diagnosis was 55 years (mean age 54 years; range: $29-79$ years); $78.5 \%$ were males. Functioning tumors were present in $14 \%$ of cases. No genetic syndrome was found. Primary was in the foregut in $57 \%(16 / 28)$ of cases and in the hindgut in $18 \%$ $(5 / 28)$ of cases; the location of the primary was unknown in $25 \%(7 / 28)$ of cases. Previous therapy included surgery of primary tumors in eight patients (28.6\%). ENETS TNM stage was stage IV in all patients but four PD NEN were classified as stage III. Metastases involved lymph nodes (79\%), liver (64\%), bones (32\%), and lungs (18\%). Increased levels of plasma CGA and NSE or urinary
5HIAA were registered in 36,39 , and $14 \%$ respectively of all cases. SRS, performed in 14 patients, was positive in ten patients (71\%). FDG-PET, performed in six cases, was positive in all.

\section{Pathological characterization}

On morphological grounds and according to the terminology proposed for this study, $42.8 \%(12 / 28)$ of cases were diagnosed as G3-WDNET and 57.2\% (16/28) as G3-LCNEC as detailed in Table 2. The characteristics of the study population according to the differentiation pattern are reported in Tables 1 and 2 . The diagnosis was made on biopsies or surgical specimens. As expected, biopsies were only more frequently available in G3-LCNEC, which present more aggressively and only scarcely undergo surgery. The main pathological parameters, with the nature of the tissue specimens available for study, are given in Table 2. Focal necrosis was found in ten of the 28 cases, including four WDNET and six LCNEC. Necrosis was diffuse in six cases of LCNEC (50\%); one case of WDNET also showed extensive necrosis but of ischemic nature.

Median mitotic count and Ki67 index tended to be higher in G3-LCNEC than in G3-WDNET but the difference was not statistically significant (Table 2 and Fig. 2). However, all tumors with Ki67 index above $60 \%$ presented with morphological features diagnostic for G3-LCNEC.

Because the pathological classification was based on biopsies in $50 \%$ of cases, especially in the case of G3-LCNEC, we attempted to confirm the pathological

Table 2 Pathological characteristics according to tumor differentiation status.

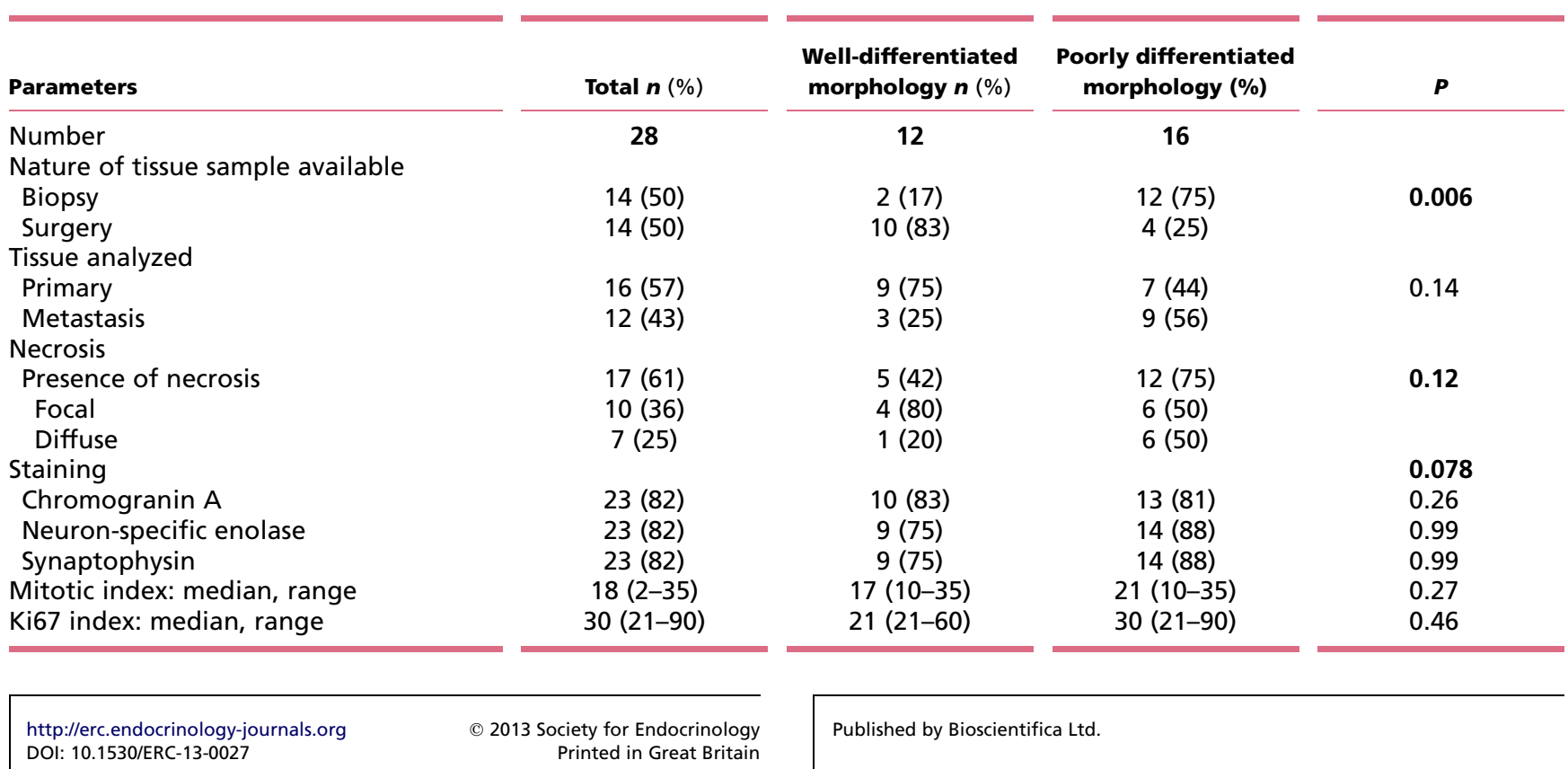




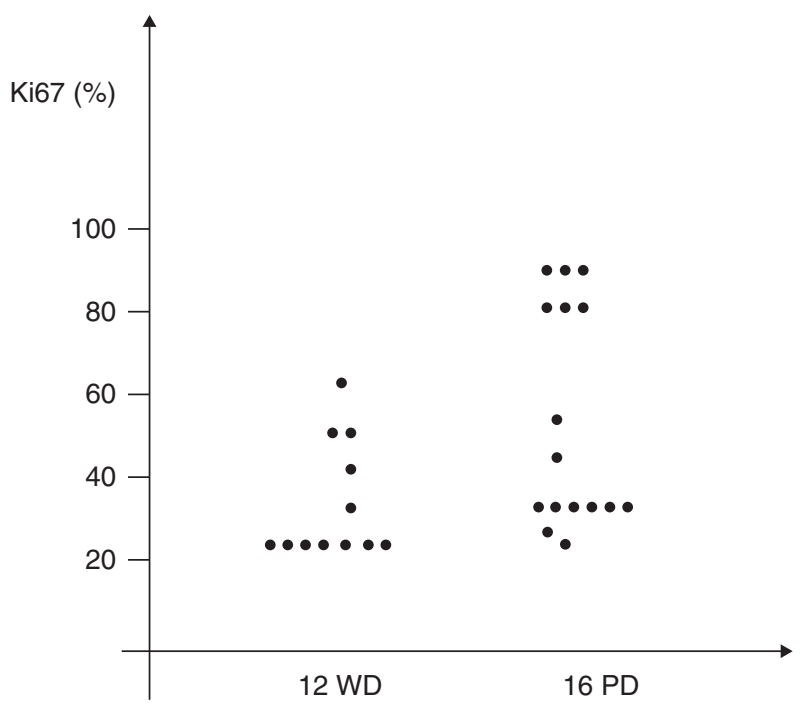

Figure 2

Ki67 distribution according to morphology at pathology.

reports by analyzing the diagnostic and prognostic behavior of these patients. G3-WDNET were functioning in $25 \%$ of cases; $42 \%$ were associated with increased serum CGA levels. In these patients, seven octreoscan of eight performed were positive (88\%). In contrast, only $6 \%$ of G3LCNEC were functioning and $31 \%$ had increased serum CGA levels. Only three octreoscan of six (50\%) performed in G3-LCNEC were positive (Table 1).

\section{Results of cisplatin-based chemotherapy}

Cisplatin-based chemotherapy was administrated as firstline therapy in ten patients (two G3-WDNET and eight G3LCNEC) or second-line therapy in ten other patients (two G3-WDNET and eight G3-LCNEC). The median total dose of platinum salts was $160 \mathrm{mg}$ (mean $240 \mathrm{mg}$, range: 140$550 \mathrm{mg}$ ). The median number of cycles was four (mean: 4; range 1-6). RECIST response to chemotherapy is given in Table 3. All five responders were G3-LCNEC patients: three CR were observed including two out of four patients with stage III carcinomas and two PR of 12 stage IV patients. No response was observed in the four treated G3-WDNET but stabilization in three and progressive disease in one.

\section{Overall survival}

The median follow-up of the studied population was 23 months (mean: 31 months; range: 4-86 months). Deaths occur in 20 cases (71.4\%) including 17 deaths related to the progression of disease and three due to other causes. Median OS for the whole population was 15.96 months (95\% CI, 11.86-20.07). Median OS for G3-WDNET or G3-LCNEC was 41 months (95\% CI, 10.04-71.96) or 17 months (95\% CI, 6.54-27.45) respectively $(P=0.34)$. A short survival $(<2$ years) was observed in $25 \%$ of G3-WDNET and $62.5 \%$ of G3-LCNEC $(P=0.049)$ (Figs 3 and 4$)$.

\section{Discussion}

To the best of our knowledge, this study is the first dedicated to the subgroup of GEP and lung NEN defined by a G3 histological grade, as defined according to the ENETS criteria initially established for GEP tumors. Despite its limitations (less number of patients due to the rarity of such cases, probable recruitment bias due to the predominant referral of aggressive cases to our institution, and high number of biopsies that may result in diagnostic biases), our study brings strong evidence that this subgroup of GEP and lung NEN is heterogeneous and contains both morphologically well and poorly differentiated tumors with different diagnostic features, prognosis, and sensitivity to treatment.

In our series, G3 GEP and thoracic NEN accounts for $17 \%$ of all first-line metastatic NEN handled over a 5-year period of time. In addition, selection of patients was based on the requisite of a pathological review and an entire follow-up in our institution since diagnosis. This figure is in the upper range of previous publications using the same restrictive inclusion criteria, which reported a 6-33\% frequency of G3 NEN according to ENETS proposals (Pape et al. 2008, Niederle et al. 2010, Hentic et al. 2011,

Table 3 RECIST analysis of cisplatin-based chemotherapy as a function of the differentiation pattern

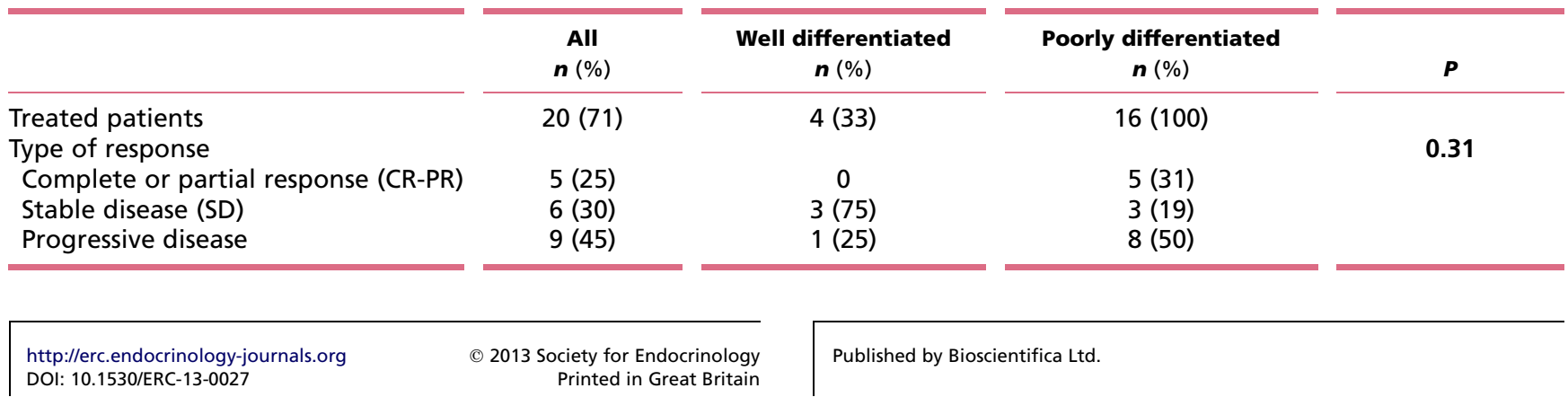




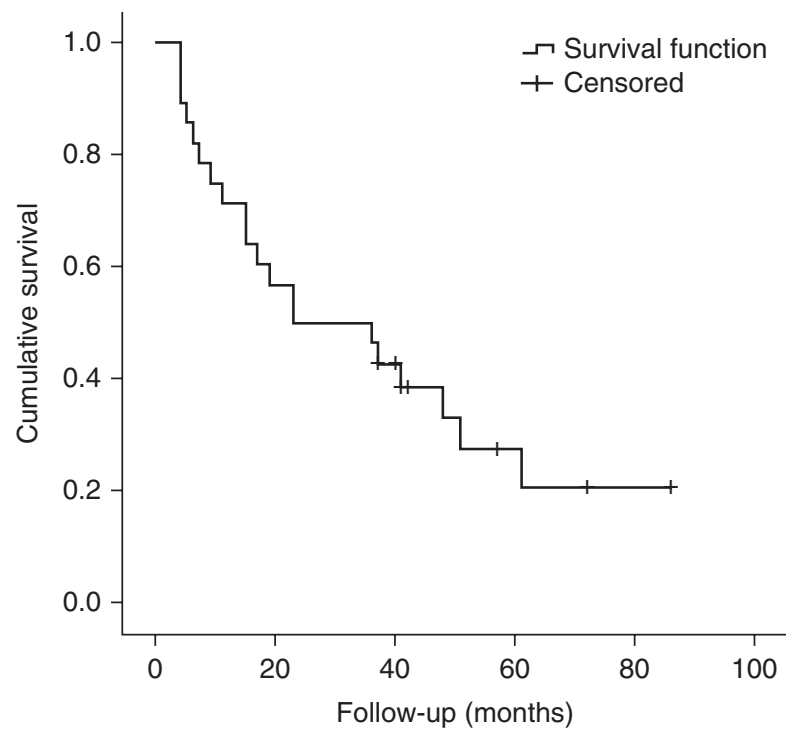

Figure 3

Cumulative survival of patients with G3 ENETS grading.

Jann et al. 2011, Panzuto et al. 2011). The highest percentages were observed in two of these series in which untreated or metastatic GEP-NEN patients were enrolled (Hentic et al. 2011, Panzuto et al. 2011). Interestingly, in four of these publications, the number of G3 ENETS patients was higher than that of PD NEC, suggesting that these two entities do not strictly overlap and do not constitute synonyms (Niederle et al. 2010, Hentic et al. 2011, Jann et al. 2011, Panzuto et al. 2011).

Demographic characteristics of G3 GEP and thoracic NEN demonstrate a predominance of male patients. Primaries were mainly located in the foregut $(57 \%)$ or hindgut (18\%). Functioning syndromes were rare, found in $14 \%$ of cases. When measured, elevated plasma levels of CGA or urinary levels of 5HIAA were observed only in 36 or $10.7 \%$ of the study patients. In contrast, NSE was found elevated in 39\% of this subgroup of patients in line with a more aggressive behavior (Baudin et al. 1998, Yao et al. 2011). At functional imaging, $71 \%$ of cases showed positive SRS uptake, in contrast to $21 \%$ with positive PET FDG uptake, but this procedure was performed in only a minority of patients. Finally, the distribution of distant metastases was in keeping with the clinical experience, except for an unexpectedly high rate of bone metastases. These characteristics did not resemble the typical presentations of either low-grade well-differentiated neoplasms or small-cell NEC. For instance, the absence of midgut primaries and male predominance do not mirror classic metastatic low-grade well-differentiated GEP neoplasms in which ileum is the most frequent primary location and sex ratio is around one. This point is even better illustrated by the median OS of our patients, which is higher than the 8-month median OS usually observed in metastatic poorly differentiated NEC (Moertel et al. 1991, Mitry et al. 1999, Yamazaki et al. 2005, Hainsworth et al. 2006) but is still lower than expected for metastatic well-differentiated GEP-NEN, for which the 5 -year survival is about 50\% (Durante et al. 2009, Hentic et al. 2011).

The reason of this 'atypical' presentation is given by the analysis of tumor morphology. Indeed, well-differentiated and poorly differentiated morphological features were found in 42.8 and $57.2 \%$ of cases respectively, showing that G3 histological grade is compatible with either differentiation status. This important result means that a very high proliferative activity, as defined by G3 grading according to the ENETS proposals, should not be considered as synonymous of poorly differentiated NEC. This implies that a new category of high-grade NEN defined by the combination of G3 histological grade and well-differentiated morphological features should be created. In our study, the presence of organoid features, the nuclear characteristics, and the absence of diffuse or multifocal necrosis were found to be the best criteria to discriminate well-differentiated from poorly differentiated

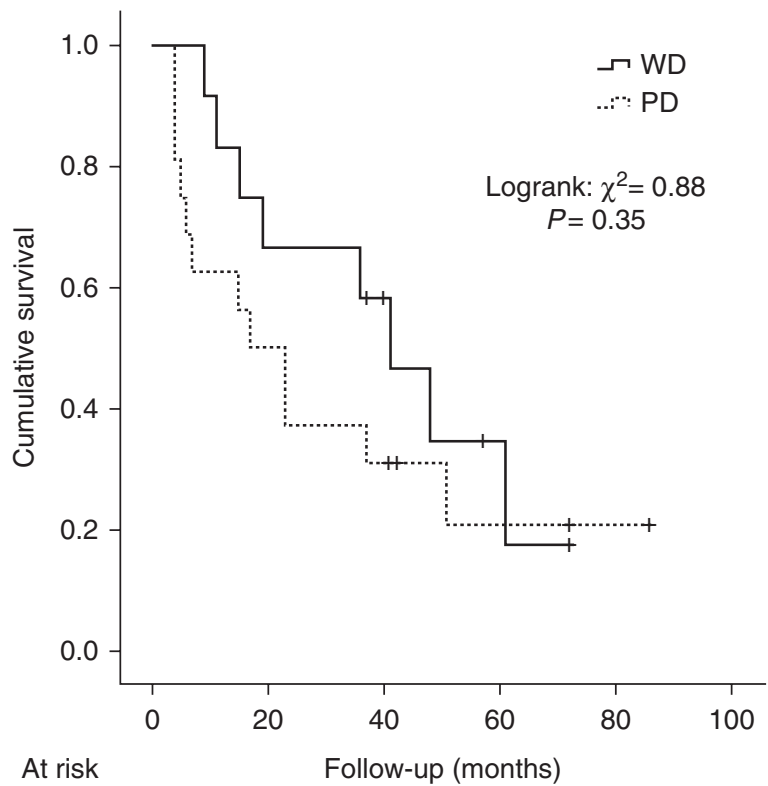

$\begin{array}{lrrrr}- & 12 & 8 & 5 & 1 \\ \cdots \cdots & 16 & 8 & 4 & 2\end{array}$

\section{Figure 4}

Cumulative survival of G3 ENETS patients according to the final pathological diagnosis. 
tumors. Indeed, G3-LCNEC were typically characterized by a diffuse architectural pattern, without organoid features, and by the presence of multifocal, confluent necrosis. Interestingly, overlaps between both mitotic count or Ki67 values, up to $60 \%$ for Ki67 labeling, suggest that combinations of both morphological criteria and proliferative index should be taken into account in establishing the final diagnosis and not strict cutoff values. In that setting, urgent second sampling should be considered when concerns are raised about the quality of specimen.

To further confirm that G3 histological grade should not be considered a single clinical entity and because the diagnosis of differentiation was performed on biopsies in a significant number of patients, we analyzed the clinical diagnostic and prognostic characteristics in relation to the morphological differentiation status in G3 patients. As expected, there were significant differences for SRS uptake between G3-WDNET and G3-LCNEC. In addition, a trend was found toward a lower number of functioning tumors and higher percentage of serum NSE increase in PD NEN, as expected again. More convincing evidence is even brought by the median OS and 2-year OS that doubled in G3 WDNET in comparison with G3-LCNEC.

Finally, response to cisplatin-based chemotherapy was also different according to the morphological differentiation status. Twenty subjects were treated with cisplatin and all five responders according to RECIST were classified as G3-LCNEC. This result is in keeping with previous publications, which reported $50 \%$ or more objective response rate of cisplatin-based chemotherapy in case of poorly differentiated NEN (Moertel et al. 1991, Mitry et al. 1999, Yamazaki et al. 2005, Hainsworth et al. 2006) in contrast to $<15 \%$ for well-differentiated tumors (Moertel et al. 1991, Mitry et al. 1999, Hentic et al. 2011). The added value of cisplatin-based chemotherapy in G3-WDNET remains to be better determined in the prospective setting. Therefore, as recommended, we consider that cisplatinbased chemotherapy has to be given to G3 patients with only poorly differentiated morphology (Pavel et al. 2012).

\section{Conclusion}

We conclude that G3 ENETS GEP and thoracic nonsmall-cell NEN could constitute a heterogeneous group of tumors as regards diagnosis, prognosis, and treatment. If confirmed, future classifications may consider distinguishing two subgroups of G3 GEP and thoracic non-small-cell-type NEN according to their morphological differentiation status: G3-WDNET and G3-LCNEC. A prospective validation is ongoing.

\section{Declaration of interest}

The authors declare that there is no conflict of interest that could be perceived as prejudicing the impartiality of the research reported.

\section{Funding}

This research did not receive any specific grant from any funding agency in the public, commercial or not-for-profit sector.

\section{Author contribution statement}

F L Vélayoudom-Céphise and J Hadoux collected the data. P Duvillard and J-Y Scoazec involved in pathological review. L Foucan performed statistical analysis. C N Chougnet, S Leboulleux, D Malka, J Guigay, D Goere, T Debaere, M Schlumberger, D Planchard, D Elias, M Ducreux, and E Baudin involved in patient accrual. C Caramella involved in RECIST review. J-Y Scoazec and E Baudin designed the study. F L Vélayoudom-Céphise, $J-Y$ Scoazec, and E Baudin involved in writing of the manuscript.

\section{Acknowledgements}

The authors thank $\operatorname{Pr}$ André Lacroix (Endocrinology Division, Centre hospitalier de l'Université de Montréal) for reviewing the manuscript.

\section{References}

Abgral R, Leboulleux S, Deandreis D, Auperin A, Lumbroso J, Dromain C, Duvillard P, Elias D, de Baere T, Guigay J et al. 2011 Performance of (18)fluorodeoxyglucose-positron emission tomography and somatostatin receptor scintigraphy for high Ki67 (>/=10\%) well-differentiated endocrine carcinoma staging. Journal of Clinical Endocrinology and Metabolism 96 665-671. (doi:10.1210/jc.2010-2022)

Baudin E 2007 Gastroenteropancreatic endocrine tumors: clinical characterization before therapy. Nature Clinical Practice. Endocrinology \& Metabolism 3 228-239. (doi:10.1038/ncpendmet0425)

Baudin E, Gigliotti A, Ducreux M, Ropers J, Comoy E, Sabourin JC, Bidart JM, Cailleux AF, Bonacci R, Ruffie P et al. 1998 Neuron-specific enolase and chromogranin A as markers of neuroendocrine tumours. British Journal of Cancer 78 1102-1107. (doi:10.1038/bjc.1998.635)

Dromain C, de Baere T, Lumbroso J, Caillet H, Laplanche A, Boige V, Ducreux M, Duvillard P, Elias D, Schlumberger M et al. 2005 Detection of liver metastases from endocrine tumors: a prospective comparison of somatostatin receptor scintigraphy, computed tomography, and magnetic resonance imaging. Journal of Clinical Oncology 23 70-78. (doi:10.1200/JCO.2005.01.013)

Durante C, Boukheris H, Dromain C, Duvillard P, Leboulleux S, Elias D, de Baere T, Malka D, Lumbroso J, Guigay J et al. 2009 Prognostic factors influencing survival from metastatic (stage IV) gastroenteropancreatic well-differentiated endocrine carcinoma. Endocrine-Related Cancer 16 585-597. (doi:10.1677/ERC-08-0301)

Ekeblad S, Skogseid B, Dunder K, Oberg K \& Eriksson B 2008 Prognostic factors and survival in 324 patients with pancreatic endocrine tumor treated at a single institution. Clinical Cancer Research 14 7798-7803. (doi:10.1158/1078-0432.CCR-08-0734)

Faggiano A, Sabourin JC, Ducreux M, Lumbroso J, Duvillard P, Leboulleux S, Dromain C, Colao A, Schlumberger M \& Baudin E 2007 Pulmonary and extrapulmonary poorly differentiated large cell neuroendocrine carcinomas: diagnostic and prognostic features. Cancer 110 265-274. (doi:10.1002/cncr.22791)

Hainsworth JD, Spigel DR, Litchy S \& Greco FA 2006 Phase II trial of paclitaxel, carboplatin, and etoposide in advanced poorly differentiated

Published by Bioscientifica Ltc. 
neuroendocrine carcinoma: a Minnie Pearl Cancer Research Network Study. Journal of Clinical Oncology 24 3548-3554. (doi:10.1200/JCO. 2005.05.0575)

Hentic O, Couvelard A, Rebours V, Zappa M, Dokmak S, Hammel P, Maire F, O'Toole D, Levy P, Sauvanet A et al. 2011 Ki-67 index, tumor differentiation, and extent of liver involvement are independent prognostic factors in patients with liver metastases of digestive endocrine carcinomas. Endocrine-Related Cancer 18 51-59. (doi:10.1677/ ERC-09-0319)

Jann H, Roll S, Couvelard A, Hentic O, Pavel M, Muller-Nordhorn J, Koch M, Rocken C, Rindi G, Ruszniewski P et al. 2011 Neuroendocrine tumors of midgut and hindgut origin: tumor-node-metastasis classification determines clinical outcome. Cancer 117 3332-3341. (doi:10.1002/cncr. 25855)

Leboulleux S, Dromain C, Vataire AL, Malka D, Auperin A, Lumbroso J, Duvillard P, Elias D, Hartl DM, De Baere T et al. 2008 Prediction and diagnosis of bone metastases in well-differentiated gastro-enteropancreatic endocrine cancer: a prospective comparison of whole body magnetic resonance imaging and somatostatin receptor scintigraphy. Journal of Clinical Endocrinology and Metabolism 93 3021-3028. (doi:10.1210/jc.2008-0459)

Lepage C, Bouvier AM, Phelip JM, Hatem C, Vernet C \& Faivre J 2004 Incidence and management of malignant digestive endocrine tumours in a well defined French population. Gut 53 549-553. (doi:10.1136/gut. 2003.026401)

Lim E, Yap YK, De Stavola BL, Nicholson AG \& Goldstraw P 2005 The impact of stage and cell type on the prognosis of pulmonary neuroendocrine tumors. Journal of Thoracic and Cardiovascular Surgery 130 969-972. (doi:10.1016/j.jtcvs.2005.05.041)

Madeira I, Terris B, Voss M, Denys A, Sauvanet A, Flejou JF, Vilgrain V, Belghiti J, Bernades P \& Ruszniewski P 1998 Prognostic factors in patients with endocrine tumours of the duodenopancreatic area. Gut 43 422-427. (doi:10.1136/gut.43.3.422)

Mitry E, Baudin E, Ducreux M, Sabourin JC, Rufie P, Aparicio T, Lasser P, Elias D, Duvillard P, Schlumberger M et al. 1999 Treatment of poorly differentiated neuroendocrine tumours with etoposide and cisplatin. British Journal of Cancer 81 1351-1355. (doi:10.1038/sj.bjc.6690325)

Modlin IM, Oberg K, Chung DC, Jensen RT, de Herder WW, Thakker RV, Caplin M, Delle Fave G, Kaltsas GA, Krenning EP et al. 2008 Gastroenteropancreatic neuroendocrine tumours. Lancet Oncology 9 61-72. (doi:10.1016/S1470-2045(07)70410-2)

Moertel CG, Kvols LK, O'Connell MJ \& Rubin J 1991 Treatment of neuroendocrine carcinomas with combined etoposide and cisplatin. Evidence of major therapeutic activity in the anaplastic variants of these neoplasms. Cancer 68 227-232. (doi:10.1002/10970142(19910715)68:2<227::AID-CNCR2820680202>3.0.CO;2-I)

Niederle MB, Hackl M, Kaserer K \& Niederle B 2010 Gastroenteropancreatic neuroendocrine tumours: the current incidence and staging based on the WHO and European Neuroendocrine Tumour Society classification: an analysis based on prospectively collected parameters. EndocrineRelated Cancer 17 909-918. (doi:10.1677/ERC-10-0152)

Panzuto F, Boninsegna L, Fazio N, Campana D, Pia Brizzi M, Capurso G, Scarpa A, De Braud F, Dogliotti L, Tomassetti P et al. 2011 Metastatic and locally advanced pancreatic endocrine carcinomas: analysis of factors associated with disease progression. Journal of Clinical Oncology 29 2372-2377. (doi:10.1200/JCO.2010.33.0688)

Pape UF, Berndt U, Muller-Nordhorn J, Bohmig M, Roll S, Koch M, Willich SN \& Wiedenmann B 2008 Prognostic factors of long-term outcome in gastroenteropancreatic neuroendocrine tumours. Endocrine-Related Cancer 15 1083-1097. (doi:10.1677/ERC-08-0017)
Pavel M, Baudin E, Couvelard A, Krenning E, Oberg K, Steinmuller T, Anlauf M, Wiedenmann B \& Salazar R 2012 ENETS Consensus Guidelines for the management of patients with liver and other distant metastases from neuroendocrine neoplasms of foregut, midgut, hindgut, and unknown primary. Neuroendocrinology 95 157-176. (doi:10.1159/000335597)

Rindi G, Azzoni C, La Rosa S, Klersy C, Paolotti D, Rappel S, Stolte M, Capella C, Bordi C \& Solcia E 1999 ECL cell tumor and poorly differentiated endocrine carcinoma of the stomach: prognostic evaluation by pathological analysis. Gastroenterology 116 532-542. (doi:10.1016/S0016-5085(99)70174-5)

Rindi G, Kloppel G, Alhman H, Caplin M, Couvelard A, de Herder WW, Erikssson B, Falchetti A, Falconi M, Komminoth P et al. 2006 TNM staging of foregut (neuro)endocrine tumors: a consensus proposal including a grading system. Virchows Archiv 449 395-401. (doi:10.1007/s00428-006-0250-1)

Rindi G, Kloppel G, Couvelard A, Komminoth P, Korner M, Lopes JM, McNicol AM, Nilsson O, Perren A, Scarpa A et al. 2007 TNM staging of midgut and hindgut (neuro) endocrine tumors: a consensus proposal including a grading system. Virchows Archiv 451 757-762. (doi:10.1007/s00428-007-0452-1)

Rindi G, Klimstra DS, Arnold R, Kloppel G, Bosman FT, Komminoth P, Capella C \& Solcia E 2010 Nomenclature and classification of neuroendocrine neoplasms of the digestive system. In WHO Classification of Tumours of the Digestive System, pp 13-14. Eds FT Bosman, F Carneiro, RH Hruban \& ND Theise. Lyon: IARC.

Solcia E, Klppel G, Sobin LH \& Williams ED 2000 Histological typing of endocrine tumours. 2nd edn, pp 61-68. New York, NY, USA: Springer-Verlag.

Strosberg J, Gardner N \& Kvols L 2009 Survival and prognostic factor analysis in patients with metastatic pancreatic endocrine carcinomas. Pancreas 38 255-258. (doi:10.1097/MPA.0b013e3181917e4e)

Therasse P, Arbuck SG, Eisenhauer EA, Wanders J, Kaplan RS, Rubinstein L, Verweij J, Van Glabbeke M, van Oosterom AT, Christian MC et al. 2000 New guidelines to evaluate the response to treatment in solid tumors. European Organization for Research and Treatment of Cancer, National Cancer Institute of the United States, National Cancer Institute of Canada. Journal of the National Cancer Institute 92 205-216. (doi:10.1093/jnci/92.3.205)

Travis WD, Rush W, Flieder DB, Falk R, Fleming MV, Gal AA \& Koss MN 1998 Survival analysis of 200 pulmonary neuroendocrine tumors with clarification of criteria for atypical carcinoid and its separation from typical carcinoid. American Journal of Surgical Pathology 22 934-944. (doi:10.1097/00000478-199808000-00003)

Travis WD CT, Corrin B, Shimosato Y \& Brambilla E 1999 In collaboration with Sobin LH and pathologists from 14 countries. World Health Organization International Histological Classification of Tumours. Histological Typing of Lung and Pleural Tumours, 3rd edn. Springer-Verlag.

Yamazaki S, Sekine I, Matsuno Y, Takei H, Yamamoto N, Kunitoh H, Ohe Y, Tamura T, Kodama T, Asamura H et al. 2005 Clinical responses of large cell neuroendocrine carcinoma of the lung to cisplatin-based chemotherapy. Lung Cancer 49 217-223. (doi:10.1016/j.lungcan.2005.01.008)

Yao JC, Hassan M, Phan A, Dagohoy C, Leary C, Mares JE, Abdalla EK, Fleming JB, Vauthey JN, Rashid A et al. 2008 One hundred years after "carcinoid": epidemiology of and prognostic factors for neuroendocrine tumors in 35,825 cases in the United States. Journal of Clinical Oncology 26 3063-3072. (doi:10.1200/JCO.2007.15.4377)

Yao JC, Pavel M, Phan AT, Kulke MH, Hoosen S, St Peter J, Cherfi A \& Oberg KE 2011 Chromogranin A and neuron-specific enolase as prognostic markers in patients with advanced pNET treated with everolimus. Journal of Clinical Endocrinology and Metabolism 96 3741-3749. (doi:10.1210/jc.2011-0666)

Received in final form 24 June 2013

Accepted 11 July 2013

Made available online as an Accepted Preprint

11 July 2013 http://erc.endocrinology-journals.org DOI: 10.1530/ERC-13-0027
(C) 2013 Society for Endocrinology Printed in Great Britain 